\title{
Scaffolds magnéticos de hidroxiapatita-magnetita como enxerto ósseo: uma prospecção científica e tecnológica
}

\section{Magnetic scaffolds of hydroxyapatite-magnetite as bone graft: a scientific survey}

Jaqueline dos Santos Ferro ${ }^{1 *}$, Hitalo de Jesus Bezerra da Silva², Valdeci Bosco dos Santos ${ }^{3}$, Débora dos Santos Tavare ${ }^{4}$, Cristiane Xavier Resende ${ }^{1}$

\begin{abstract}
RESUMO
A incorporação de nanopartículas magnéticas em scaffolds para regeneração tecidual tem sido investigada devido a demanda por scaffolds inteligentes e efetivos. O objetivo deste estudo foi realizar uma prospecção tecnológica, de artigos e patentes, sobre scaffolds magnéticos de hidroxiapatita-magnetita como enxerto ósseo. Os resultados mostraram que o uso de nanopartículas magnéticas nesta área é recente, com potencial tecnológico e promissor para o tratamento de perdas ósseas.
\end{abstract}

Palavras-chave: Hidroxiapatita; Magnetita; Scaffolds; Propriedades Magnéticas.

\begin{abstract}
The incorporation of magnetic nanoparticles into scaffolds for tissue regeneration has been investigated, due to the demand for intelligent and effective scaffolds. The objective of this study was to carry out a technological prospection of articles and patents on magnetic scaffolds of hydroxyapatite-magnetite as bone graft. The results showed that the use of magnetic nanoparticles in this area is recent, with technological potential and promising for the treament of bone loss.
\end{abstract}

Keywords: Hydroxyapatite; Magnetite; Scaffolds; Magnetic Properties.

\section{INTRODUÇÃO}

A engenharia tecidual óssea consiste no uso de arcabouços tridimensionais (scaffolds), que devem estimular o crescimento de células e de um novo tecido na região lesionada (ROLIM et al., 2018, SHI et al., 2019). Nos últimos anos, observou-se uma demanda por scaffolds mais inteligentes e efetivos, ou seja, que respondam a algum tipo

\footnotetext{
${ }^{1}$ Universidade Federal de Sergipe - UFS, Programa de Pós-Graduação em Ciência e Engenharia de Materiais (P2CEM).

*E-mail: jaq.ferro@ hotmail.com

${ }^{2}$ Universidade Federal do Pernambuco - UFPE, Programa de Pós-Graduação em Ciência de Materiais (PPGMTR).

${ }^{3}$ Universidade Federal do Piauí - UFPI, Departamento de Engenharia de Materiais.

${ }^{4}$ Universidade Federal de Sergipe - UFS, Departamento de Educação em Saúde.
} 
de estímulo: físico, magnético, elétrico ou mecânico (GE et al., 2019; TANASA et al., 2020).

Os scaffolds magnéticos vêm sendo pesquisados devido a sua capacidade de transportar fatores solúveis, como fatores de crescimento, hormônios e polipeptídeos diretamente para o local de implantação, além de melhorar a fixação do implante e sua estabilidade. A ativação magnética por um campo externo aplicado pode ser usada para transportar/manter os fatores de crescimento específicos no local da lesão (RUSSO et al., 2018).

A incorporação de nanopartículas em scaffolds para aplicações na regeneração de tecidos passou a ser investigada recentemente, com destaque para as nanopartículas superparamagnéticas, que são nanopartículas magnéticas com tamanho inferior a $30 \mathrm{~nm}$. Estas apresentam cada partícula como um domínio magnético, não retém nenhuma magnetização, além de não haver agregação de nanopartículas após a retirada do campo magnético, mostrando alto potencial para aplicações in vivo (ORTOLANI et al., 2017; SHUAI et al., 2020a).

As nanopartículas magnéticas incorporadas aos scaffolds de hidroxiapatita (HA), principal mineral constituinte do osso, tem potencial ainda maior de promover a regeneração óssea, visto que o campo magnético modifica a composição das proteínas e ativam eficientemente a via de sinalização celular Mitogen Activated Protein Kinase (MAPK)/ Extracellular Regulatory Protein Kinase (ERK). Desta forma, estimula a proliferação dos osteoblastos, células responsáveis pela síntese e mineralização da matriz óssea, e aumenta a solubilidade da HA em meio fisiológico (HEIDARI et al., 2015; ORTOLANI et al., 2017; HE et al., 2017; ZHU et al., 2019; TORGBO e SUKYAI, 2019). Durante todo o processo de reparo ósseo, muitos receptores na superfície celular podem ser ativados, elevando a atividade celular e promovendo a formação óssea (SHUAI et al., 2020a). Entretanto, a biocompatibilidade in vivo e o potencial osteocondutor desses scaffolds não foram completamente elucidados (HEIDARI et al., 2015; RUSSO et al., 2018).

Dentre os diferentes tipos de nanopartículas magnéticas, a magnetita $\left(\mathrm{Fe}_{3} \mathrm{O}_{4}\right)$ é o único óxido metálico aprovado pelo Departamento de Saúde e Serviços Humanos dos Estados Unidos- Food and Drug Administration (FDA)- para uso clínico e tem despertado significativo interesse em aplicações biomédicas. Isso se deve a suas propriedades paramagnéticas, excelente biocompatibilidade e atoxicidade, alta rigidez e resistência 
específica, além de grande área de superfície específica, que pode ser usada para melhorar as propriedades mecânicas dos scaffolds (SHUAI et al., 2020b). Além disso, os íons de ferro presentes nas nanopartículas de óxidos de ferro, após a metabolização, são adicionados aos depósitos de ferro no corpo e incorporados no sangue pelos eritrócitos e ligam-se à hemoglobina (DÍAZ et al., 2018). Dessa forma, as nanopartículas de magnetita podem ser absorvidas, fagocitadas e metabolizadas pelas células, e, quando utilizadas, mesmo sem um campo magnético, são capazes de aumentar a eficácia do reparo tecidual, promovendo estímulos mecânicos para a formação óssea, diferenciação osteogênica e a regeneração óssea in vivo (XIA et al., 2018).

O número crescente de trabalhos experimentais nesta área de pesquisa indica o grande potencial de estratégias magnéticas para a engenharia tecidual óssea (HEIDARI et al., 2015; ORTOLANI et al., 2017; HE et al, 2017; DÍAZ et al., 2018; GE et al., 2019; TORGBO e SUKYAI, 2019; CHAVES et al., 2021). Apesar disso, estudos sistemáticos que direcionem sobre os avanços nessa área ainda são escassos, especialmente em relação aos scaffolds de magnetita-hidroxiapatita (ORTOLANI et al., 2017).

Dessa forma, a prospecção tecnológica e a revisão criteriosa da literatura científica são ferramentas importantes que podem auxiliar no processo de tomada de decisão tanto por parte das empresas quanto por gestores da área da saúde, que buscam por melhores estratégias para atender ao seu público-alvo (MAYERHOFF, 2008). Nesse sentido, o objetivo desse trabalho foi realizar uma prospecção tecnológica, a fim de analisar o cenário nacional e internacional em relação às pesquisas envolvendo scaffolds magnéticos de hidroxiapatita-magnetita para terapia de perdas ósseas, relacionando os documentos de patentes depositados e os artigos científicos publicados, destacando as suas propriedades, aplicações e potencial tecnológico.

\section{MATERIAL E MÉTODOS}

A prospecção científica e tecnológica foi realizada a partir de documentos disponíveis nas bases de patentes e de artigos científicos publicados sobre a temática "scaffold magnético de hidroxiapatita-magnetita como enxerto ósseo". As pesquisas das patentes foram realizadas a partir de três bancos de dados: o Instituto Nacional da Propriedade Industrial (INPI) do Brasil, Organização Mundial da Propriedade Intelectual 
(World Intellectual Property Organization - WIPO), Escritório Europeu de Patentes (European Patent Office - EPO) que foram definidos de acordo com acessibilidade e confiabilidade dos dados disponíveis. A busca por artigos científicos foi realizada nas plataformas Web of Science (Coleção Principal da Thomson Reuters Scientific), Scopus (Elsevier) e Scielo (Scientific Electronic Library Online). O levantamento foi realizado em abril de 2021, utilizando as combinações de descritores em inglês: "hydroxyapatite and magnetite and scaffold and magnetic", sendo incluso as patentes e os artigos que apresentassem esses termos no título e/ou no resumo. As mesmas palavras-chave, porém, escritas na língua portuguesa, foram utilizadas na base de patente nacional.

Por fim, foram realizadas leituras dos resumos das patentes e artigos encontrados e, quando necessário, a leitura do trabalho na íntegra. Não houve critérios de exclusão nas buscas, sendo incluídos no levantamento todos os resultados referidos nas bases no momento da pesquisa.

\section{RESULTADOS E DISCUSSÃO}

A Figura 1 mostra o fluxograma da busca de artigos e patentes. Após a remoção de 16 duplicatas, seguida da remoção de 07 artigos que não representavam tratamento ósseo com scaffolds de HA-magnetita, 43 artigos foram incluídos na revisão. Quanto as patentes, após análise documental, apenas 14 foram incluídas na análise.

Figura 1 - Fluxograma da busca de artigos e patentes

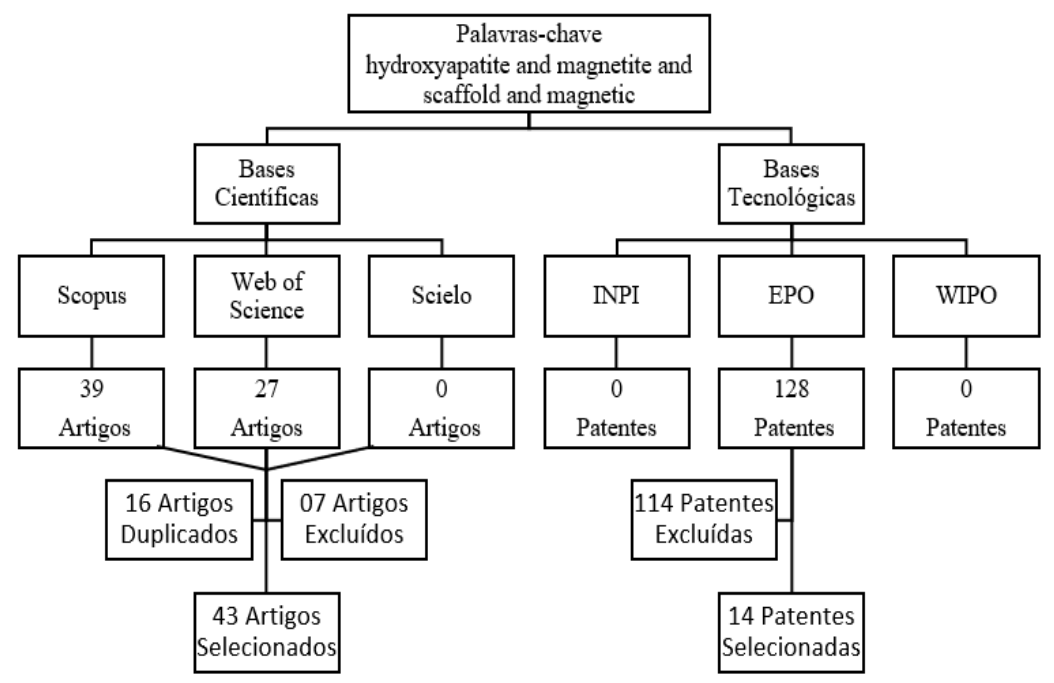


A distribuição de artigos científicos e patentes por ano de publicação é apresentada na Figura 2. O depósito de patentes foi efetuado durante o período de 2004 a 2019, sem registros de depósitos nos anos de 2007, 2015 e 2018. Este período converge com os anos de publicações dos artigos, de 2007 a 2021, concomitante a uma maior produção científica sobre a temática. No primeiro artigo publicado em 2007, os autores propuseram a inoculação de células do estroma da medula óssea em scaffolds de hidroxiapatita com nanopartículas de magnetita para aplicação na engenharia tecidual óssea (SHIMIZU et al., 2007). Nos anos seguintes observa-se um aumento razoável nas produções sobre a temática com destaque para os anos de 2019, 2017 e 2015. Já a primeira patente depositada no ano 2004 (US2004210282A1), trata de métodos para produção de dispositivos magnéticos usados no tratamento de tecidos e células.

Figura 2 - Distribuição de artigos e patentes por ano de publicação

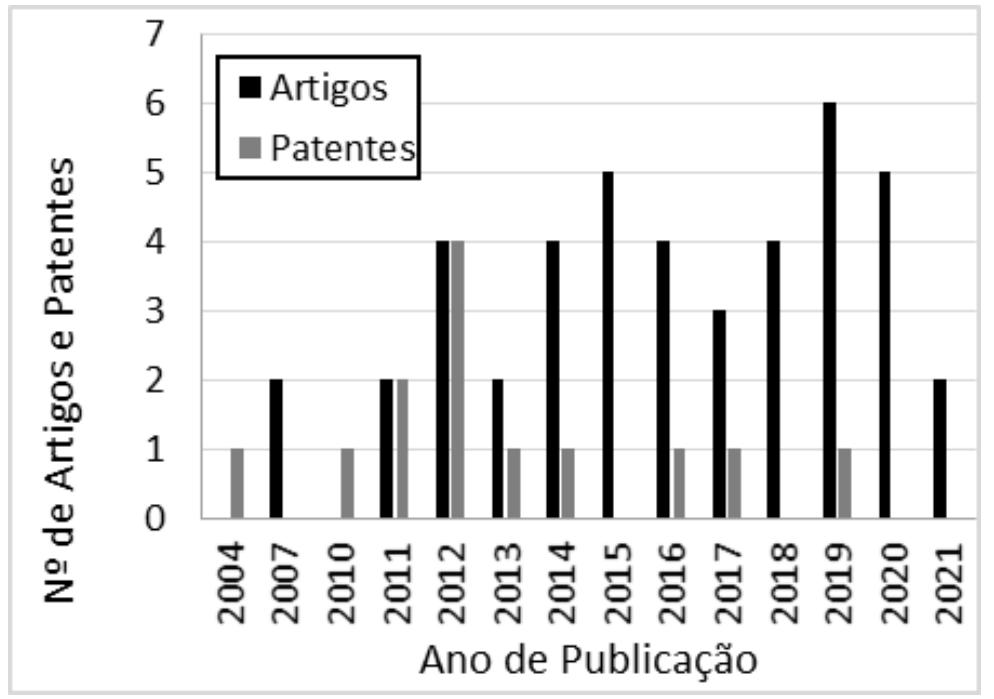

Fonte: Autores (2021)

Os artigos de Heidari et al. (2015), Russo et al. (2018), Torgbo e Sukyai (2019), abordaram a produção, caracterização e utilização dos scaffolds de hidroxiapatitamagnetita para o tratamento de patologias ósseas, destacando a excelente biocompatibilidade, osteocondução, atoxicidade e biodegradabilidade dos biomateriais. Já as pesquisas de Pistone et al. (2014), Zhao et al. (2019), Sahmani et al. (2020), Chaves et al. (2021), destacam a utilização dos scaffolds de hidroxiapatita-magnetita associados a liberação de fármacos para a regeneração óssea, incluindo os fármacos clodronato, 
doxorrubicina, ibuprofeno e sinvastatina, respectivamente. Os estudos demonstram que os nanocompósitos magnéticos sintetizados atuam, de fato, como um sistema de liberação de fármacos, sendo biocompatíveis e osteoindutores, e com potencial na engenharia de tecido ósseo. A hidroxiapatita não atua apenas como um carreador de fármacos, mas melhora a estabilidade do sistema de administração, promovendo uma liberação controlada.

As patentes do ano de 2010 (WO2010141027A1) e do ano de 2012 (US2012035608A1), referem-se a produção de scaffolds eletromagnéticos biocompatíveis para aplicação na engenharia de tecidos e na medicina regenerativa, com destaque especial aos métodos de produção desses biomateriais eletromagnéticos que mimetizam tecidos e órgãos. Enquanto a patente do ano de 2013 (US2013129634A1) reporta sobre o processo de produção da hidroxiapatita magnética dopada com íons de ferro, destacando o seu potencial na reconstituição óssea e cartilaginosa, como transportador de substâncias biológicas e/ou fármacos e como um agente de contraste para imagens diagnósticas. Os autores afirmam que a hidroxiapatita magnética pode ser carreada com diversas substâncias biológicas, como proteínas, genes, células-tronco, fatores de crescimento e fármacos, sob o controle de um campo magnético externo para liberação de substâncias biológicas ou fármacos durante o processo de regeneração óssea.

Ao se verificar a proporção de publicações de artigos por área, Figura 3, constatou-se que as principais áreas de publicação foram Ciências dos Materiais com 37\% dos artigos encontrados, Engenharia com 15\% e Engenharia química com 11\%. Dados que podem ser explicados pela relação da temática com as áreas destacadas, que estão diretamente ligadas ao desenvolvimento de novos biomateriais para aplicação na engenharia de tecidos e na medicina regenerativa. 
Figura 3 - Proporção de publicações de artigos por área de estudo

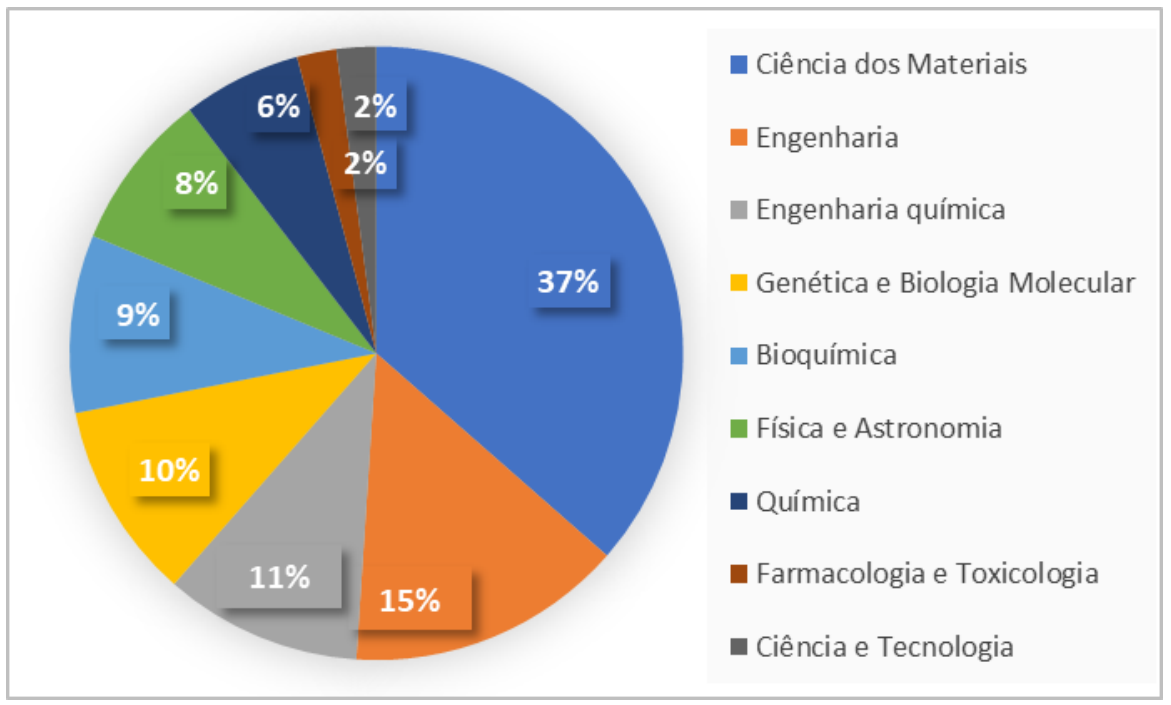

Fonte: Autores (2021)

Analisou-se ainda a distribuição de publicações de artigos e patentes por país de origem, Figura 4. A China e a Itália destacam-se com 12 e 11 publicações de artigos, respectivamente. Enquanto que o Brasil apresenta apenas 01 publicação, que foi divulgada recentemente em 2021, na qual os autores abordaram a preparação, a caracterização e a aplicação de scaffolds constituídos por hidroxiapatita, quitosana e magnetita para liberação do fármaco sinvastatina como um biomaterial potencial para aplicação no tratamento de perdas ósseas (CHAVES et al., 2021). Verifica-se, de modo geral, uma baixa produção científica sobre a temática, tanto a nível nacional quanto internacional. Em adição, apenas 6 países depositaram patentes. Dentre estes, destacamse os Estados Unidos e a China, com 7 e 3 registros de depósitos patentários, respectivamente.

Figura 4 - Distribuição de artigos e patentes publicados por país

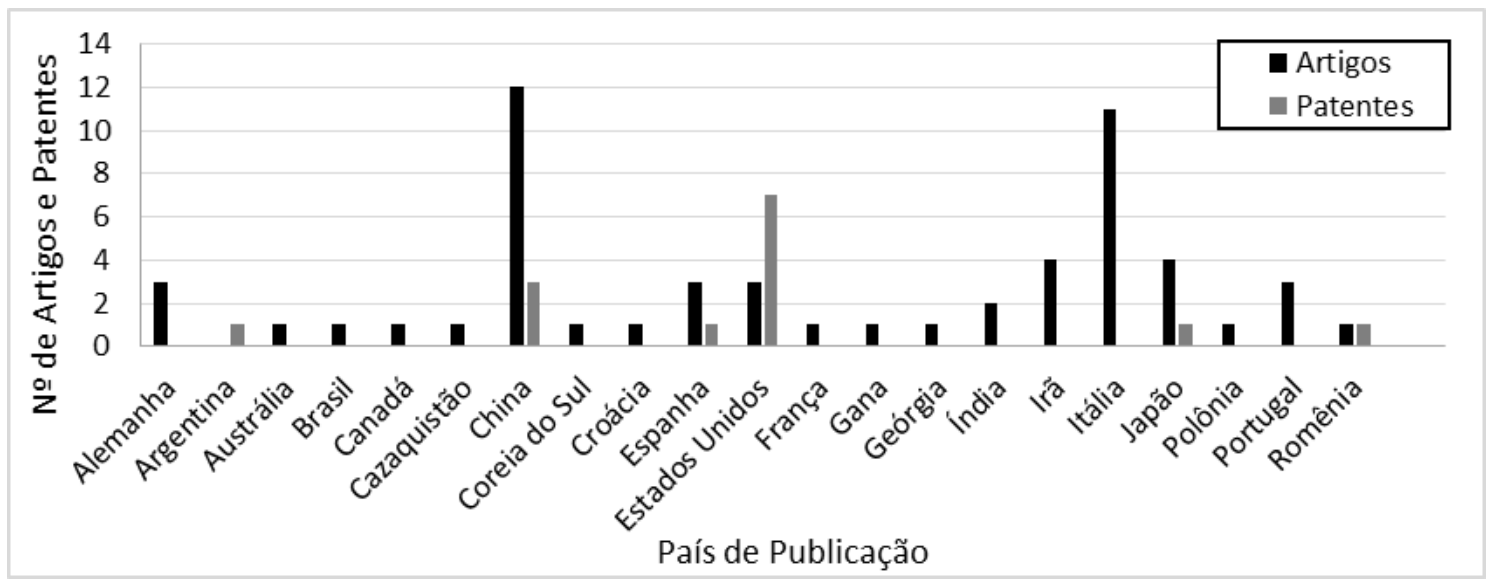


Fonte: Autores (2021)

Os dados mostram que os países com destaque na produção de artigos e patentes têm alto poder econômico e crescimento populacional estável, com Produto Interno Bruto (PIB) entre os dez maiores do mundo. Segundo Pereira (2011), fatores como apoio governamental, investimento e pesquisadores qualificados sustentam o crescimento socioeconômico e a inovação tecnológica. Coccia (2013) afirma que a análise das variáveis envolvidas na pesquisa e desenvolvimento tecnológico dos países é complexa, pois, o desenvolvimento tecnológico é avaliado por indicadores como: crescimento demográfico, políticas públicas e questões culturais de cada país. A quantidade de artigos e patentes produzidas por países demonstra o nível de seu desenvolvimento socioeconômico, estando diretamente associado a qualidade de vida da população. No Brasil, a falta de políticas públicas consistentes e investimentos em pesquisa e tecnologia impactam no baixo número de produção de artigos e na escassez de patentes (ANDRADE et al., 2020), conforme demonstrado na Figura 4.

Enquanto que a Argentina apresenta somente um depósito de patente do ano de 2017 (EP3222711A1), desenvolvida em parceria com pesquisadores da Espanha, acerca de um método de produção de tecido artificial com incorporação de nanopartículas de magnetita, para aumentar, restaurar ou substituir (parcial ou totalmente) a atividade funcional de um órgão ou tecido danificado, como o osso. No entanto, não foi observada a produção de artigos. Em relação ao Brasil, nenhum depósito de patente foi registrado nesta linha de pesquisa. Dessa forma, um número significativo de países apresenta publicações de artigos, entretanto, não depositaram patentes, o que evidencia que os pesquisadores preferem publicar artigos a patentear seus resultados.

\section{CONCLUSÃO}

O levantamento dos dados científicos mostrou que a utilização de nanopartículas magnéticas para o tratamento de perdas ósseas se insere como uma área interdisciplinar, além de ser um tema recente, como verificado pelo reduzido número de publicações de artigos e patentes sobre scaffolds magnéticos de hidroxiapatita-magnetita para a regeneração óssea, com participação de pesquisadores de áreas diversas. A China e a Itália 
se destacaram na produção de artigos. Em contrapartida, os Estados Unidos foram o país que mais realizou depósito de patentes sobre o assunto. Pode-se afirmar que estudos sobre scaffolds magnéticos de hidroxiapatita-magnetita tornam-se importantes para $\mathrm{o}$ desenvolvimento científico pelo seu potencial tecnológico e por serem promissores para o tratamento de perdas ósseas na área de oncologia e na liberação de fármacos. Por isso, pesquisas para o desenvolvimento desses materiais devem receber mais incentivo.

\section{REFERÊNCIAS}

ANDRADE, G. S., ANDRADE, D. B., LIMA, G. G. et al. Prospecção tecnológica de quitosana, fibroína e goma xantana como biomateriais aplicáveis em scaffolds-3D. Revista GEINTEC, vol. 10, p. 5279-5288, 2020.

CHAVES, A. V., FREIRE, R. M., FEITOSA, V. P. et al. Hydroxyapatite-Based Magnetic Bionanocomposite as Pharmaceuticals Carriers in Chitosan Scaffolds. J. Compos. Sci., v. 5, 2021.

COCCIA, M. Driving forces of technological change: The relation between population growth and technological innovation. Technological Forecasting and Social Change, v. 82, p.52-65, 2013.

DÍAZ, E., VALLE, M. B., RIBEIRO, S. et al. Development of Magnetically Active Scaffolds for Bone Regeneration. Nanomaterials (Basel), v. 8, 2018.

GE, J., ZHAI, M., ZHANG, Y. et al. Biocompatible Fe3O4/chitosan scaffolds with high magnetism. International Journal of Biological Macromolecules, v. 128, 2019.

HE, J., HU, H., ZENG, X. et al. A magnetic hydroxyapatite composite scaffoldbased magnetic therapy for bone repair: in experimental study in canis lupus familiaris.

Regenerative Biomaterials, v. 39, 2017.

HEIDARI, F., BAHROLOLOOM, M. A., VASHAEE, D. et al. In situ preparation of iron oxide nanoparticles in natural hydroxyapatite/chitosan matrix for bone tissue engineering application. Ceramics International, v. 41, p. 3094-3100, 2015.

MAYERHOFF, Z.D.V.L. Uma análise sobre os estudos de prospecção tecnológica. Cadernos de Prospecção, v.1, p. 7-9, 2008.

ORTOLANI, A., BIANCHI, M., MOSCA, M. et al. The prospective opportunities offered by magnetic scaffolds for bone tissue engineering: a review. Joints. v. 4 p. 228$235,2017$. 
PEREIRA, J. M. Política de ciência, tecnologia e inovação: uma avaliação da gestão do sistema de proteção à propriedade intelectual no Brasil. Independent Journal of Management \& Production (IJM\&P), v. 02, 2011.

PISTONE, A., IANNAZZO, D., PANSERI, S. et al. Hydroxyapatite-magnetiteMWCNT nanocomposite as a biocompatible multifunctional drug delivery system for bone tissue engineering. Nanotechnology, v. 25, 2014.

ROLIM, A. E., KAMALI, A., MOSHIRI, A. H. et al. Chitosan scaffolds-PhysicoChemical and biological properties for bone repair. Revista Virtual de Quimica, v. 10, p. 211-228, 2018.

RUSSO, A., BIANCHI, M., SARTORI, M. et al. Bone regeneration in a rabbit critical femoral defect by means of magnetic hydroxyapatite macroporous scaffolds. J Biomed Mater Res B Appl Biomater, v. 106, p. 546-554, 2018.

SAHMANI, S., KHANDAN, A., SABER-SAMANDARI, S. et al. Effect of magnetite nanoparticles on the biological and mechanical properties of hydroxyapatite porous scaffolds coated with ibuprofen drug. Materials Science and Engineering: C, v. 111, 2020.

SHI, D., SHEN, J., ZHANG, Z. et al. Preparation and properties of dopamine-modified alginate/chitosan-hydroxyapatite scaffolds with gradient structure for bone tissue engineering. Journal of Biomedical Materials Research, v. 107, 2019.

SHIMIZU, K ., ITO, A., HONDA, H. Mag-seeding of rat bone marrow stromal cells into porous hydroxyapatite scaffolds for bone tissue engineering. J Biosci Bioeng, 2007.

SHUAI, C., CHENG, Y., YANG, W. et al. Magnetically actuated bone scaffold: Microstructure, cell response and osteogenesis. Composites Part B, v. 192, 2020a.

SHUAI, C., YANG, W., HE, C. et al. A magnetic micro-environment in scaffolds for stimulating bone regeneration. Materials e Design, v. 185, $2020 \mathrm{~b}$.

TANASA, E., ZAHARIA, C., HUDITA, A. et al. Impact of the magnetic field on 3T3E1 preosteoblasts inside smart silk fibroin-based scaffolds decorated with magnetic nanoparticles. Materials Science e Engineering C, v. 110, 2020.

TORGBO, S., SUKYAI, P. Fabrication of microporous bacterial cellulose embedded with magnetite and hydroxyapatite nanocomposite scaffold for bone tissue engineering. Materials Chemistry and Physics, v. 237, 2019.

XIA, Y., SUN, J., ZHAO, L. et al. Magnetic field and nano-scaffolds with stem cells to enhance bone regeneration. Biomaterials, v. 183, 2018.

ZHAO, Y., FANA, T., CHEN, J. et. al. Magnetic bioinspired micro/nanostructured composite scaffold for bone regeneration. Colloids and Surfaces B: Biointerfaces, v. 174, p. 70-79, 2019. 
ZHU, Y., JIANG, P., LUO, B. et al. Dynamic protein corona influences immunemodulating osteogenesis in magnetic nanoparticle (MNP)-infiltrated bone regeneration scaffolds in vivo. Nanoscale, v. 11, 2019.

Recebido em: 10/10/2021

Aprovado em: 15/11/2021

Publicado em: 20/11/2021 